\title{
Overestimation of carboplatin doses is avoided by radionuclide GFR measurement
}

\begin{abstract}
AJ Craig*,', J Samol' ${ }^{2}$, SD Heenan ${ }^{3}$, AG Irwin ${ }^{4}$ and A Britten ${ }^{4}$
'Joint Department of Physics, Royal Marsden NHSFT, Downs Road, Sutton, Surrey SM2 5PT, UK; ²Department of Medical Oncology, St George's Hospital, Blackshaw Road, Tooting, London SWI 7 OQT, UK: ${ }^{3}$ Nuclear Medicine Department, Lanesborough Wing, St George's Hospital, Blackshaw Road, Tooting, London SWI 7 OQT, UK; ${ }^{4}$ Medical Physics and Bioengineering Department, Knightsbridge Wing, St George's Hospital, Blackshaw Road, Tooting, London SWI7 OQT, UK
\end{abstract}

BACKGROUND: Glomerular filtration rate (GFR) is used in the calculation of carboplatin dose. Glomerular filtration rate is measured using a radioisotope method (radionuclide GFR (rGFR)), however, estimation equations are available (estimated GFR (eGFR)). Our aim was to assess the accuracy of three eGFR equations and the subsequent carboplatin dose in an oncology population.

PATIENTS AND METHODS: Patients referred for an rGFR over a 3-year period were selected; eGFR was calculated using the Modification of Diet in Renal Disease (MDRD), Chronic Kidney Disease Epidemiology Collaboration (CKD-EPI) and Cockcroft-Gault (CG) equations. Carboplatin doses were calculated for those patients who had received carboplatin chemotherapy. Bias, precision and accuracy were examined.

RESULTS: Two hundred and eighty-eight studies met the inclusion/exclusion criteria. Paired $t$-tests showed significant differences for all

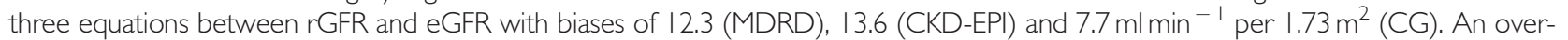
estimation in carboplatin dose was seen in $81 \%, 87 \%$ and $66 \%$ of studies using the MDRD, CKD-EPI and CG equations, respectively. CONCLUSION: The MDRD and CKD-EPI equations performed poorly compared with the reference standard rGFR; the CG equation showed smaller bias and higher accuracy in our oncology population. On the basis of our results we recommend that the rGFR should be used for accurate carboplatin chemotherapy dosing and where unavailable the use of the CG equation is preferred. British Journal of Cancer (2012) 107, 1310-1316. doi:10.1038/bjc.2012.393 www.bjcancer.com

Published online 30 August 2012

(c) 2012 Cancer Research UK

Keywords: carboplatin; glomerular filtration rate; EDTA

Carboplatin is an alkylating chemotherapy agent (Souhami and Tobias, 2005) belonging to the group of platinum cytotoxics and is mainly used not only in combination with other cytotoxic drugs but also as a single agent to treat common malignancies, such as lung cancer, gynaecological, gastrointestinal, urological cancers, and many other cancers including curative malignancies, such as Hodgkin's and non-Hodgkin's lymphomas. Myelosuppression is carboplatin's dose-limiting toxicity and the pre-treatment renal function affects the severity of this. The renal clearance of carboplatin is closely related to the glomerular filtration rate (GFR) and to this end the dose is adjusted using the GFR in the Calvert formula (Calvert et al, 1989).

The Calvert formula was developed using ${ }^{51} \mathrm{Cr}$-EDTA as the GFR measurement method, but equations may be applied to calculate an estimated GFR (eGFR). The National Kidney Foundation Kidney Disease Outcomes Quality Initiative (K/DOQI) (National Kidney Foundation, 2002) recommends the use of the eGFR along with markers of kidney damage for staging chronic kidney disease (CKD). These estimation equations are now commonly used in clinical practice for various clinical applications (Lamb et al, 2005; Thomsen, 2007; Craig et al, 2011; National Kidney Disease Education Program, 2012).

*Correspondence: AJ Craig; E-mail: allison.craig@rmh.nhs.uk Received I8 April 2012; revised 6 August 2012; accepted 6 August 2012; published online 30 August 2012
The eGFR is an estimate of the GFR using a combination of variables such as serum creatinine, gender, age, weight and ethnicity, and offers the advantage of being a cheaper, easier and faster alternative to the ${ }^{51} \mathrm{Cr}$-EDTA. There are several estimation equations available for clinical use. The MDRD eGFR equation was introduced by the Modification of Diet in Renal Disease study group in 1999 (Levey et al, 1999, 2000) and re-expressed for use with standardised serum creatinine values in 2005 (Levey et al, 2005, 2006). It was derived based on a patient group with CKD and is recommended by K/DOQI (National Kidney Foundation, 2002) and the UK Guidelines for CKD (National Collaborating Centre for Chronic Conditions, 2008) for classifying CKD. The Chronic Kidney Disease Epidemiology Collaboration (CKD-EPI) eGFR formula was developed in 2009 (Levey et al, 2009; Stevens et al, 2010) to be more accurate than the MDRD equation for a GFR $>60 \mathrm{ml} \mathrm{min}^{-1}$ per $1.73 \mathrm{~m}^{2}$. The Cockcroft-Gault (CG) equation has been in use in clinical practise for many years (Cockcroft and Gault, 1976; Rostoker et al, 2007) and is often used when prescribing anticancer drugs, although in our cancer centre at St George's it is more commonly used between chemotherapy cycles for monitoring renal function.

At our cancer centre it is standard to use ${ }^{51} \mathrm{Cr}$-EDTA as the baseline renal function measurement before the start of chemotherapy, especially when using carboplatin. There are centres (Hematology/Oncology Pharmacy association, 2010) that are using estimation equations such as the MDRD equation for calculating carboplatin doses. The CG equation is widely used for calculating carboplatin doses. 
There have been few studies investigating the use of estimation equations in oncology patients (De Lemos et al, 2006; SeronieVivien et al, 2006; Barry et al, 2009; Shord et al, 2009; Jennings et al, 2010; Redal-Baigorri et al, 2011; Ainsworth et al, 2012). Some of these studies investigated the use of the MDRD and CG equations to calculate the carboplatin dosage (De Lemos et al, 2006; Barry et al, 2009; Shord et al, 2009; Ainsworth et al, 2012) and other non-carboplatin chemotherapy agents (Jennings et al, 2010). None of these studies have investigated the use of the CKDEPI equation in calculating carboplatin dosing compared with ${ }^{51} \mathrm{Cr}$-EDTA as the gold standard. In this single-centre analysis of retrospective data, we have compared the GFR results from the ${ }^{51} \mathrm{Cr}$-EDTA with those calculated from the MDRD, CKD-EPI and CG equations in oncology patients treated for a wide range of cancer types. The carboplatin doses calculated from the radionuclide GFR (rGFR) and the eGFR equations were then compared.

\section{PATIENTS AND METHODS}

This study was approved by our local Research Office as clinical audit and informed consent was waived due to the retrospective nature of the study.

\section{Subjects}

Records of all patients referred for an rGFR between September 2005 and September 2008 were reviewed retrospectively, in total 1352 studies.

Inclusion criteria were as follows: patients referred from Oncology who were treated with chemotherapy following their rGFR (if multiple studies were available for the same patient the first was chosen); serum creatinine measurement within 7 days of the rGFR; serum creatinine of $60 \mu \mathrm{moll}^{-1}$ and over; and patients aged over 20 years (the corrected GFR ranges for adults start at 20 years (Fleming et al, 2004)).

Exclusion criteria were as follows: patients with missing information and patients with a creatinine level of under $60 \mu \mathrm{moll}^{-1}$, which is the lower limit of our laboratory normal range. The Food and Drugs Administration released guidance (Food and Drug Administration, 2012) on the use of isotope dilution mass spectrometry (IDMS) standardised serum creatinine values for calculating carboplatin doses as they appeared to underestimate low serum creatinine values compared with older methods - they recommended the capping of doses for low serum creatinine values. To avoid any dose capping or rounding of serum creatinine values, we have excluded these low serum creatinine values $\left(<60 \mu \mathrm{moll}^{-1}\right)$ from our study.

\section{rGFR measurement and eGFR calculation}

${ }^{51} \mathrm{Cr}$-EDTA (3 MBq) was administered by intravenous injection and plasma samples taken at approximately 120 and $240 \mathrm{~min}$ post-injection. Plasma samples were counted in a Wallac Wizard
1480 automatic gamma counter (Wallac, Turku, Finland) for $600 \mathrm{~s}$ per sample.

The rGFR was calculated using the slope-intercept method, as recommended by the UK national guidelines (Fleming et al, 2004) with the Brochner-Mortensen correction (Brochner-Mortensen, 1972). The Haycock formula was used for body surface area (BSA) estimation for all studies to allow the calculation of the corrected rGFR and the absolute rGFR. The kinetic Jaffe method, which is calibrated against IDMS values, was used for measuring the serum creatinine for all studies. The eGFR were calculated for all patients using the four-variable MDRD equation (Levey et al, 1999, 2000, 2005, 2006), the CKD-EPI equation (Levey et al, 2009; Stevens et al, 2010) and the modified CG equation (Cockcroft and Gault, 1976; Rostoker et al, 2007) to calculate BSA corrected eGFR values (Table 1).

The patients were split into two groups - those who received carboplatin chemotherapy and those who received non-carboplatinbased chemotherapy. For those who had received carboplatin chemotherapy the dosing was calculated using the Calvert formula (Calvert et al, 1989) (Table 1). The eGFR values were BSA corrected to get absolute values for use in the Calvert equation. It is normal practice to round the carboplatin dose to account for the degree of accuracy possible with ampoules and vials (Plumridge and Sewell, 2001), at our cancer centre doses are rounded up to the nearest $10 \mathrm{mg}$.

\section{Statistical analysis}

The rGFR results were plotted against the eGFR results and least squares linear regression performed to calculate $R^{2}$. Bland-Altman analysis (Bland and Altman, 1986) was performed for the rGFR vs the eGFR. The means \pm s.d. were given and paired $t$-tests were carried out. The bias was given as the mean difference between the eGFR and rGFR values and the precision as the s.d. of the differences. The biases were also calculated over four rGFR ranges: $<30 \mathrm{ml} \mathrm{min}^{-1}$ per $1.73 \mathrm{~m}^{2}, \quad 30-59 \mathrm{ml} \mathrm{min}^{-1}$ per $1.73 \mathrm{~m}^{2}$, $60-89 \mathrm{ml} \mathrm{min}^{-1}$ per $1.73 \mathrm{~m}^{2}$, and $\geqslant 90 \mathrm{ml} \mathrm{min}^{-1}$ per $1.73 \mathrm{~m}^{2}$. A $P$-value of $<0.05$ was considered statistically significant. The maximum differences between the rGFR and eGFR were examined. Accuracy was described as the number of studies within 10,30 and $50 \%$ of the rGFR values.

For carboplatin dosing, the means and range for each GFR method were investigated and Bland-Altman analysis was performed. The accuracy was examined as the number of studies within $5,10,20,30$ and $50 \%$ of that calculated from the rGFR values. All statistical analyses were performed using Analyse-it for Microsoft Excel (2008).

\section{RESULTS}

\section{Study demographics}

Applying the study criteria resulted in 288 rGFR studies, $24 \%$ of the patients were inpatients. The range of corrected rGFR values

Table I Equations used for calculation of eGFR and carboplatin dosing

\begin{tabular}{ll}
\hline MDRD & eGFR $\left(\mathrm{ml} \mathrm{min}^{-1}\right.$ per $\left.1.73 \mathrm{~m}^{2}\right)=175 \times \mathrm{SCr}^{-1.154} \times \mathrm{A}^{-0.203} \times 0.742$ (if female $) \times 1.212$ (if black) \\
CKD-EPI & $\left\{\right.$ eGFR $\left(\mathrm{ml} \mathrm{min}^{-1}\right.$ per $\left.1.73 \mathrm{~m}^{2}\right)=141 \times \min (\mathrm{SCr} / \kappa, 1)^{\alpha} \times \max (\mathrm{SCr} / \kappa, 1)^{-1.209} \times 0.993^{\text {Age }} \times 1.018($ if female $) \times 1.159($ if black $)$ \\
Modified CG & eGFR $\left(\mathrm{ml} \mathrm{min}^{-1} \operatorname{per} 1.73 \mathrm{~m}^{2}\right)=\frac{(140-A) \times \text { weight }}{72 \times \mathrm{SCr}} \times \frac{1.73}{\mathrm{BSA}} \times 0.85$ (if female) \\
Calvert & Dose $(\mathrm{mg})=\operatorname{AUC}\left(\mathrm{mg} \mathrm{ml}^{-1} \mathrm{~min}\right) \times\left[\mathrm{GFR}\left(\mathrm{ml} \mathrm{min}^{-1}\right)+25\right]$
\end{tabular}

Abbreviations: $\mathrm{A}=$ age; $\mathrm{A} \cup \mathrm{C}=$ prescribed area under curve; $\alpha=-0.329$ for females, $-0.4 \mathrm{I}$ I for males; BSA = body surface area $\left(\mathrm{m}^{2}\right)$; eGFR $=$ estimated glomerular filtration

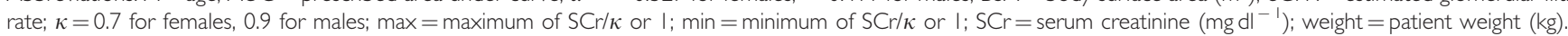


Table 2 Study demographics and clinical data

\begin{tabular}{|c|c|}
\hline & $\begin{array}{c}\text { Study data } \\
\text { Range (mean } \pm \text { s.d.) }\end{array}$ \\
\hline Male: female (\%) & $56: 44$ \\
\hline Age range at rGFR measurement (years) & $21-93(66 \pm 12)$ \\
\hline Weight (kg) & $31-131(72 \pm 17)$ \\
\hline Height $(\mathrm{cm})$ & $143-196(169 \pm 10)$ \\
\hline $\operatorname{BSA}\left(\mathrm{m}^{2}\right)$ & $1.1-2.6(1.8 \pm 0.3)$ \\
\hline $\mathrm{BMI}$ & $13-45(25 \pm 5)$ \\
\hline Serum creatinine $\left(\mu \mathrm{mol} \mathrm{I}^{-1}\right)$ & $60-637(89 \pm 48)$ \\
\hline rGFR (ml min ${ }^{-1}$ per $\left.1.73 \mathrm{~m}^{2}\right)$ & $5-128(63 \pm 20)$ \\
\hline MDRD eGFR $\left(\mathrm{ml} \mathrm{min}^{-1}\right.$ per $\left.1.73 \mathrm{~m}^{2}\right)$ & $8-149(76 \pm 23)$ \\
\hline CKD-EPI eGFR (ml min ${ }^{-1}$ per $\left.1.73 \mathrm{~m}^{2}\right)$ & $7-138(77 \pm 23)$ \\
\hline CG eGFR $\left(\mathrm{ml} \min ^{-1}\right.$ per $\left.1.73 \mathrm{~m}^{2}\right)$ & $9-153(71 \pm 24)$ \\
\hline Days between rGFR and serum creatinine & $0-7(2 \pm 2)$ \\
\hline
\end{tabular}

Abbreviations: $\mathrm{BMI}=$ body mass index; $\mathrm{BSA}=$ body surface area; $\mathrm{CG}=$ CockcroftGault; CKD-EPI=chronic kidney disease epidemiology collaboration; eGFR = estimated glomerular filtration rate; $M D R D=$ modification of diet in renal disease; rGFR = radionuclide glomerular filtration rate. Data are presented as ranges or percentage.

Table 3 Ethnicity of patients in study, data obtained from the hospital electronic patient record system (patients classify their own ethnicity)

\begin{tabular}{lc}
\hline Ethnicity & \% Of patients \\
\hline White British & 47.6 \\
White & 5.1 \\
White Irish & 3.5 \\
Indian & 1.3 \\
Black Caribbean & 4.8 \\
Black African & 2.2 \\
Bangladeshi & 0.3 \\
Pakistani & 0.5 \\
Mixed White + Black Caribbean & 0.5 \\
Mixed ethnic group & 0.3 \\
Any other Black background & 0.3 \\
Any other ethnic group & 0.5 \\
Any other White background & 4.0 \\
Asian other & 2.7 \\
Other & 0.8 \\
Patient unwilling to disclose & 0.8 \\
Unknown & 2.2 \\
\hline
\end{tabular}

were $5-128 \mathrm{ml} \mathrm{min}^{-1}$ per $1.73 \mathrm{~m}^{2}$. Full study demographics and clinical data can be found in Table 2 .

The gender and ethnicity of the patients were obtained from hospital records. The ethnicity term in the estimation equations was used for black patients (9\% of studies) as stated (Levey et al, 1999, 2009; Stevens et al, 2010) (Table 3).

\section{Comparison of MDRD, CKD-EPI and CG eGFR with rGFR}

All eGFR equations showed significant correlation with the rGFR (MDRD: $R^{2}=0.57, P<0.0001$; CKD-EPI: $R^{2}=0.59, P<0.0001$; CG: $R^{2}=0.52, P<0.0001$ ) (Figure 1). Bland-Altman plots of the eGFR data $v s$ the rGFR are shown (Figure 2), none of the biases calculated were significant (Table 4). Precisions of $15.3 \mathrm{ml} \mathrm{min}^{-1}$ per $1.73 \mathrm{~m}^{2}$ (MDRD), $14.6 \mathrm{ml} \mathrm{min}^{-1}$ per $1.73 \mathrm{~m}^{2}$ (CKD-EPI), and $16.8 \mathrm{ml} \mathrm{min}^{-1} 1.73 \mathrm{~m}^{2}$ (CG) were found. The maximum differences in rGFR and eGFR values were $88.3 \mathrm{ml} \mathrm{min}^{-1}$ per $1.73 \mathrm{~m}^{2}$ for the MDRD eGFR, $87.1 \mathrm{ml} \mathrm{min}^{-1}$ per $1.73 \mathrm{~m}^{2}$ for the CKD-EPI eGFR and $-88.0 \mathrm{ml} \mathrm{min}{ }^{-1}$ per $1.73 \mathrm{~m}^{2}$ for the CG. All equations showed significant differences in the means from the paired $t$-test $(P<0.0001)$. The GFR population accuracies for the eGFR equations can be seen in Table 5.
Of the 288 studies, 175 patients received carboplatin-based chemotherapy and 113 received non-carboplatin-based chemotherapy, no significant differences were found in the mean biases between these two groups of patients.

The studies were split up into groups depending on the cancer type: gynaecological, lung, lymphoma, upper GI, urological, melanoma, breast, colorectal, and anal cancer; merkel and germ cell tumour, leukaemia and three studies with unknown primaries. The four largest groups (gynaecological, lung, lymphoma and upper GI cancer) were examined. No differences could be seen between these four groups for the CKD-EPI eGFR, the MDRD eGFR showed a lower bias in the group with gynaecological cancer and the CG eGFR showed a higher bias for the lymphoma group.

\section{Comparison of carboplatin dosing using the different GFR methods}

The maximum prescribed dose with the rGFR was $790 \mathrm{mg}$ - this was 1150,1020 and $1120 \mathrm{mg}$ for the MDRD, CKD-EPI and CG, respectively (Table 6). The MDRD eGFR overestimated the carboplatin dosing in $81 \%$ of cases whereas the CKD-EPI overestimated in $87 \%$ of cases and the CG overestimated in $66 \%$ of cases. In all, 30, 35 and 26\% (MDRD, CKD-EPI, CG) of cases had an increase in dose of more than 20\%; 1,1 and 2\% (MDRD, CKD-EPI, CG) had a reduction in dose of more than $20 \%$. Figure 3 shows the Bland-Altman plots for the carboplatin dosing. Table 7 shows the accuracy of the calculated carboplatin doses. The average absolute percentage error found was $18 \%, 19 \%$ and $15 \%$ for the MDRD, CKD-EPI and CG, respectively.

\section{DISCUSSION}

We compared the MDRD, CKD-EPI and CG eGFR equations for a general oncology population treated at St George's cancer centre to a reference standard of ${ }^{51} \mathrm{Cr}$-EDTA rGFR; comparing GFR values and the carboplatin doses calculated from the Calvert equation (Calvert et al, 1989). The MDRD, CKD-EPI and CG estimation equations showed overestimations in GFR values, resulting in overestimations of carboplatin dosing, and limited accuracy both for the GFR value and the carboplatin dose.

Two studies (Froissart et al, 2005; Redal-Baigorri et al, 2011) showed similar precision to our study for both the MDRD and the CKD-EPI; and the CG showed a lower precision than the MDRD as seen previously (De Lemos et al, 2006). However, our study found an overestimation in the GFR from all three of these estimation equations, with the CKD-EPI demonstrating no better performance at high GFR values as previously demonstrated (Levey et al, 2009). Other studies have shown both an underestimation of GFR values (De Lemos et al, 2006; White et al, 2010) and an overestimation (Kukla et al, 2010, Poge et al, 2011). Likewise, some studies (Froissart et al, 2005; Redal-Baigorri et al, 2011) showed better accuracies in the GFR values than our study whereas Poge et al (2011) showed similar accuracies to ours for these equations. The CG equation showed the smallest mean bias and higher accuracy; the accuracy was similar to that found by Seronie-Vivien et al (2006).

In our study, no clinically significant differences in the GFR values were noted for patients receiving carboplatin-based chemotherapy regimens compared with non-carboplatin-based chemotherapy regimes. Also no clinically significant differences were noted for the four largest cancer groups in our study for the CKD-EPI equation. However, a difference was noted in the gynaecological cancer due to the all female cohort where the gender term in the MDRD equation causes a reduction in the GFR value. A higher bias was noted for lymphoma patients for the CG eGFR equation, this is thought to be the lower age range in this group. 

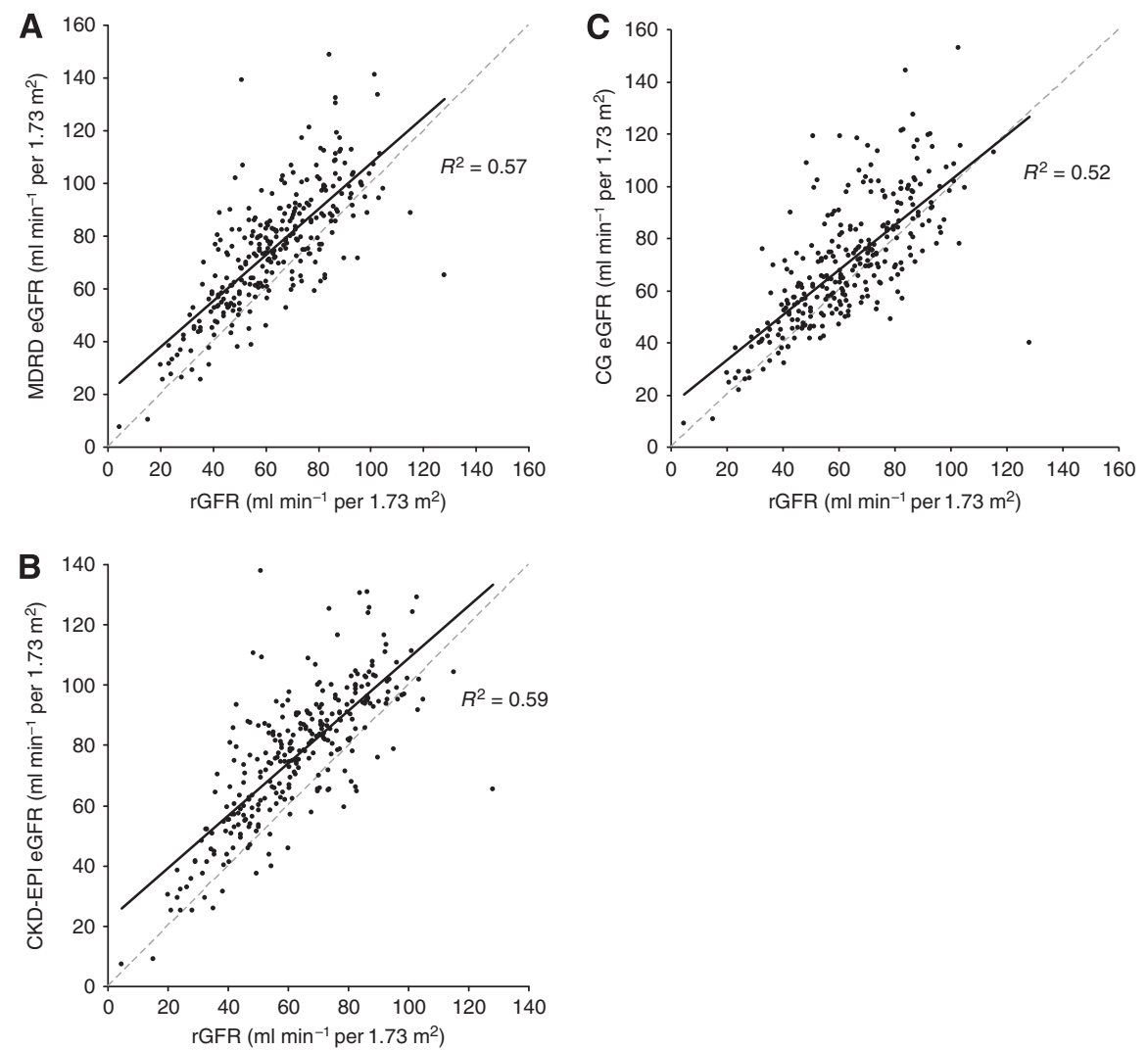

Figure I Scatter plots of rGFR plotted against (A) the eGFR calculated from the MDRD equation, (B) the eGFR calculated from the CKD-EPI equation and $(\mathbf{C})$ the eGFR calculated from the CG equation. The linear regression lines are shown as solid lines, the lines of identity are shown as dashed lines.
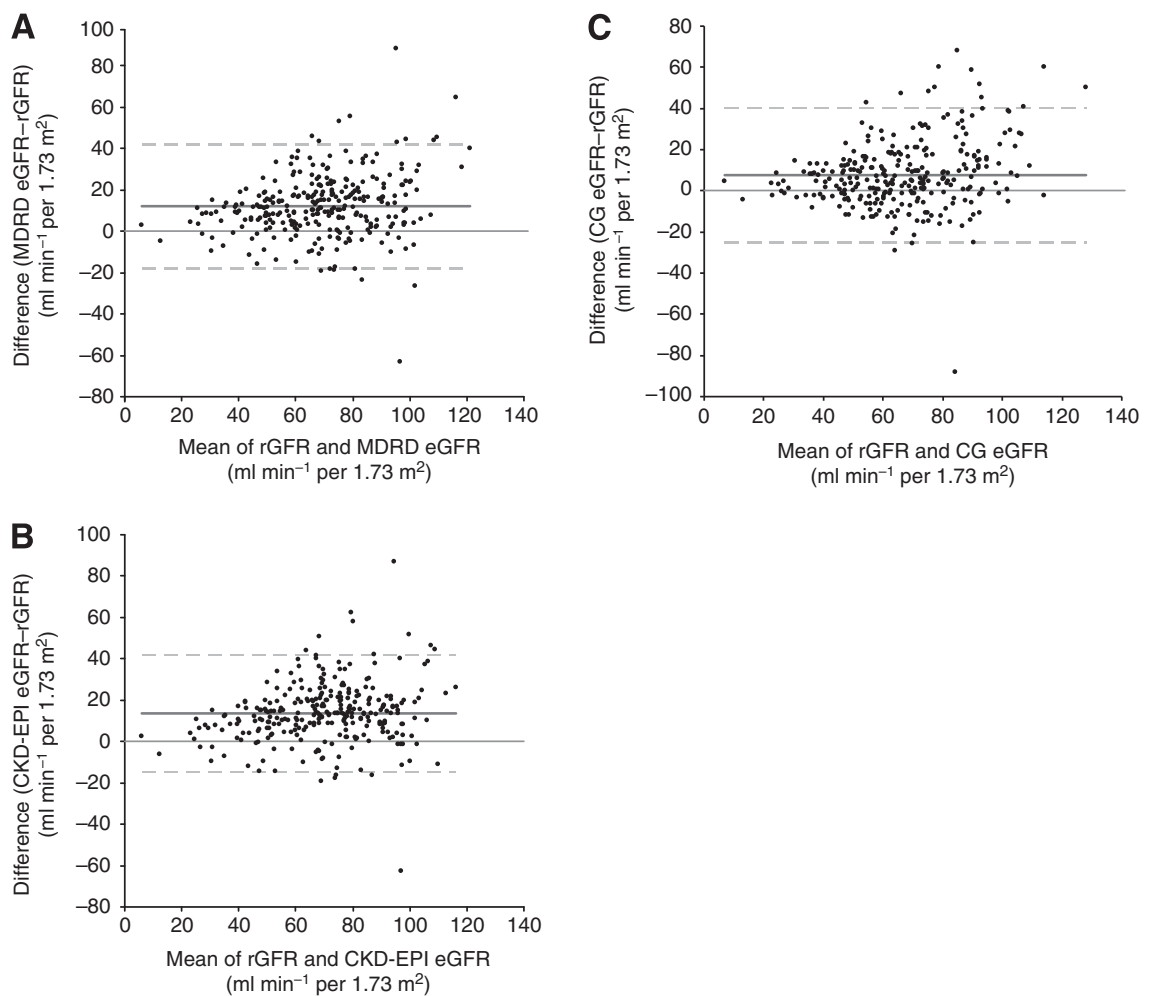

Figure 2 Bland-Altman plots of the difference of the eGFR and the rGFR against the mean of the eGFR and the rGFR. The 95\% limits of agreement are represented by the dashed lines, the lines of bias are represented by the solid lines. These are shown for (A) the MDRD eGFR (bias 12.3 ml min ${ }^{-1}$ per $1.73 \mathrm{~m}^{2} ; 95 \%$ confidence limits $-17.8: 42.3 \mathrm{ml} \mathrm{min}^{-1}$ per $1.73 \mathrm{~m}^{2}$ ), (B) the CKD-EPI eGFR (bias $13.6 \mathrm{ml} \mathrm{min}^{-1}$ per $1.73 \mathrm{~m}^{2}$; $95 \%$ confidence limits - I5.0:42.2 $\mathrm{ml} \mathrm{min}^{-1}$ per $1.73 \mathrm{~m}^{2}$ ) and (C) the CG eGFR (bias $7.7 \mathrm{ml} \mathrm{min}^{-1}$ per $1.73 \mathrm{~m}^{2} ; 95 \%$ confidence limits $-25.2: 40.6 \mathrm{ml} \mathrm{min}^{-1}$ per $1.73 \mathrm{~m}^{2}$ ). 
A

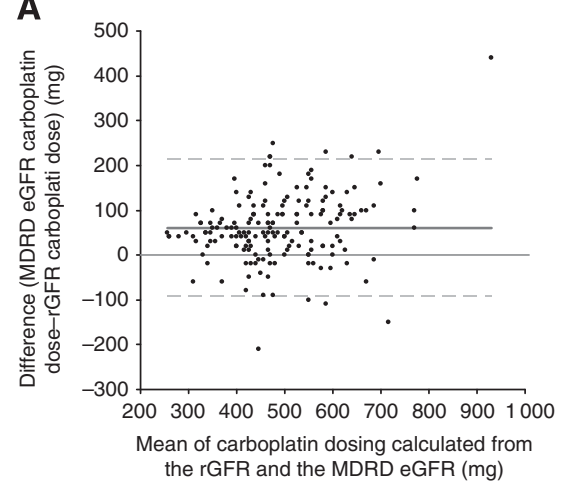

B

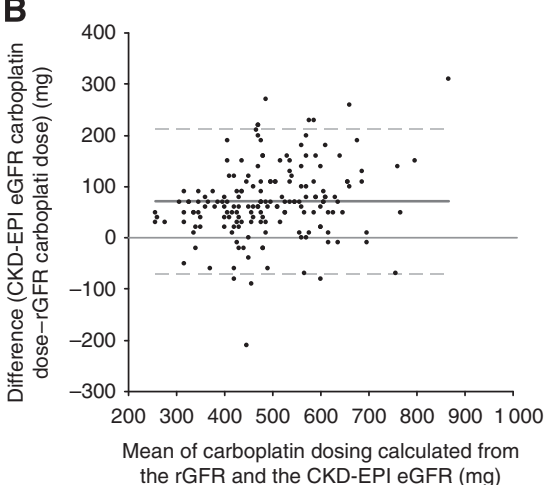

C

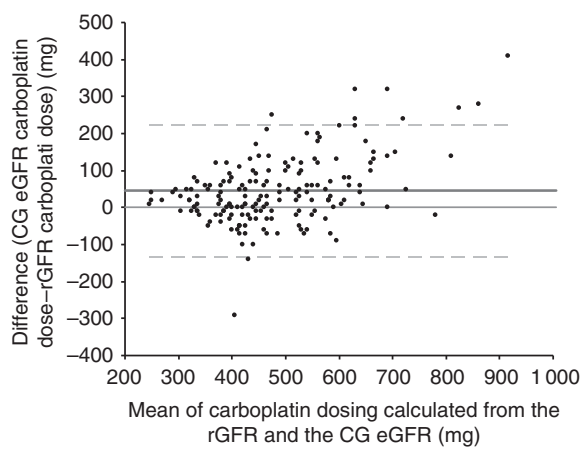

Table 7 Percentage of carboplatin doses, calculated using the eGFR, within 5, 10, 20, 30 and $50 \%$ of the carboplatin dose calculated using the rGFR

\begin{tabular}{lccccc}
\hline & \multicolumn{5}{c}{ \% Within certain percentage of rGFR carboplatin dose } \\
\cline { 2 - 6 } eGFR & $\mathbf{5}$ & $\mathbf{1 0}$ & $\mathbf{2 0}$ & $\mathbf{3 0}$ & $\mathbf{5 0}$ \\
\hline MDRD & 18 & 32 & 69 & 86 & 96 \\
CKD-EPI & 13 & 25 & 64 & 82 & 95 \\
CG & 26 & 43 & 72 & 86 & 97 \\
\hline
\end{tabular}

Abbreviations: $C G=$ Cockcroft-Gault; CKD-EPI = chronic kidney disease epidemiology collaboration; eGFR = estimated glomerular filtration rate; MDRD = modification of diet in renal disease; rGFR = radionuclide glomerular filtration rate.

developed using values calibrated to IDMS; all of our serum creatinine values are standardised to IDMS. The standardised serum creatinine values are known to underestimate serum creatinine at lower levels compared with older methods, and capping of doses for low serum creatinine values is recommended (Food and Drug Administration, 2012). Other studies (Dooley et al, 2004; Kaag and Steins, 2011) examining low creatinine values recommend rounding up low serum creatinine values for use in estimation equations. A brief look at serum creatinine values below $60 \mu \mathrm{moll}^{-1}$ in our initial patient group gave abnormally high results; these were higher for the MDRD equation than the CKDEPI equation which takes into account the serum creatinine levels within the terms of the equation. Glomerular filtration rate values of up to $875 \mathrm{ml} \mathrm{min}^{-1}$ per $1.73 \mathrm{~m}^{2}$ were calculated by the MDRD equation translating into carboplatin doses of $4060 \mathrm{mg}$. Doses of such magnitude would only be used in oncology patients treated with curative intent and followed by a stem cell autograft to allow recovery of the bone marrow (Rick et al, 2001; De Giorgi et al, 2003). When comparing the MDRD equation with the creatinine clearance calculated, Barry et al (2009) found large differences in the GFR and the calculated carboplatin dosage at low serum creatinine values. The MDRD equation was based on a patient population with CKD and this makes its usage outside this patient population questionable.

When the MDRD equation was developed (Levey et al, 1999), $88 \%$ of the patients were identified as ethnically white with under representation of ethnic minorities being a clear limitation. In our study, the patient population is ethnically much more diverse and this may well be a source of potential error. Another source of potential error is that serum creatinine measurements are not reliable in certain clinical situations including acute renal failure, pregnancy, oedematous states, muscle-wasting disease states, amputees and malnourished patients (National Collaborating Centre for Chronic Conditions, 2008), and these could not all be confidently excluded from our study.

In conclusion, we have shown that both the MDRD and the CKD-EPI estimation equations performed poorly compared with the reference standard rGFR using ${ }^{51} \mathrm{Cr}$-EDTA in a heterogeneous oncology patient population that is also ethnically diverse. We have also shown that both equations are poor across the range of common cancer types and less common cancer types treated with carboplatin-based or non-carboplatin-based chemotherapy regimens. The large inaccuracies seen in carboplatin dosing by the use of eGFR values lead us to recommend that an exogenous filtration marker, such as rGFR, should be used for accurate carboplatin chemotherapy dose calculation, however, if no rGFR is available then the use of the CG equation is preferred. 


\section{REFERENCES}

Ainsworth NL, Marshall A, Hatcher H, Whitehead L, Whitfield GA, Earl HM (2012) Evaluation of glomerular filtration rate estimation by CockcroftGault, Jeliffe, Wright and Modification of Diet in Renal Disease (MDRD) formulae in oncology patients. Ann Oncol 23(7): 1845-1853

Analyse-it for Microsoft Excel (version 2.11), Analyse-it Software, Ltd (2008). http://www.analyse-it.com/

Barry A, O'Cearbhaill R, Griffin D, Donnellan P, Keane M, Grimes H (2009) Evaluation of carboplatin dosage based on 4-variable modification of diet in renal disease equation. Ir J Med Sci 178(3): 301-307

Bland JM, Altman DG (1986) Statistical methods for assessing agreement between two methods of clinical measurement. Lancet 327(8476): 307-310

Brochner-Mortensen J (1972) A simple method for the determination of glomerular filtration rate. Scand J Clin Lab Invest 30(3): 271-274

Calvert AH, Newell DR, Gumbrell LA, O'Reilly S, Burnell M, Boxall FE, Siddik ZH, Judson IR, Gore ME, Wiltshaw E (1989) Carboplatin dosage: prospective evaluation of a simple formula based on renal function. J Clin Oncol 7(11): 1748-1756

Cockcroft DW, Gault MH (1976) Prediction of creatinine clearance from serum -creatinine. Nephron 16(1): 31-41

Craig AJ, Britten A, Heenan SD, Irwin AG (2011) Significant differences when using MDRD for GFR estimation compared to radionuclide measured clearance. Eur Radiol 21(10): 2211-2217

De Giorgi U, Papiani G, Severini G, Fiorentini G, Marangolo M, Rosti G (2003) High-dose chemotherapy in adult patient with germ cell tumours. Cancer Control 10(1): 48-56

De Lemos ML, Hsieh T, Hamata L, Levin A, Swenerton K, Djurdjev O, Vu T, $\mathrm{Hu}$ F, Conklin J, Malfair Taylor SC (2006) Evaluation of predictive formulae for glomerular filtration rate for carboplatin dosing in gynecological malignancies. Gynecol Oncol 103(3): 1063-1069

Dooley MJ, Singh S, Rischin D (2004) Rounding of low serum creatinine levels and consequent impact on accuracy of bedside estimates of renal function in cancer. Br J Cancer 90(5): 991-995

Fleming JS, Zivanovic MA, Blake GM, Burniston M, Cosgriff PS, British Nuclear Medicine Society (2004) Guidelines for the measurement of glomerular filtration rate using plasma sampling. Nucl Med Commn 25(8): 759-769

Food and Drug Administration (2012) Carboplatin Dosing. www.fda.gov/ AboutFDA.CentersOffices/OfficeofMedicalProductsandTobacco/CDER/ ucm228974.htm (accessed 24 January 2012)

Froissart M, Rossert J, Jacquot C, Paillard M, Houillier P (2005) Predictive performance of the modification of diet in renal disease and cockcroftgault equations for estimating renal function. J Am Soc Nephrol 16(3): $763-773$

Hematology/Oncology Pharmacy association (2010) Newsletter, Fall 2010. www.hoparx.org/uploads/files/newsletterfall_2010.pdf (accessed 24 January 2012)

Jennings S, De Lemos ML, Levin A, Murray N (2010) Evaluation of creatinine-based formulas in dosing adjustment of cancer drugs other than Carboplatin. J Oncol Pharm Practice 16(2): 113-119

Kaag D, Steins M (2011) Impact of rounding low serum creatinine concentration on the accuracy of carboplatin AUC dosing. EJHP Sci 17(1): $13-20$

Kukla A, El-Shahawi Y, Leister E, Kasiske B, Mauer M, Matas A, Ibrahim HN (2010) GFR-estimating models in kidney transplant recipients on a steroid-free regimen. Nephrol Dial Transplant 25: 1653-1661

Lamb EJ, Tomson CRV, Roderick PJ (2005) Estimating kidney function in adults using formulae. Ann Clin Biochem 42(5): 321-345

Levey AS, Bosch JP, Breyer Lewis J, Greene T, Rogers N, Roth D (1999) A more accurate method to estimate glomerular filtration rate from serum creatinine: a new prediction equation. Ann Intern Med 130(6): 461-470

Levey AS, Coresh J, Greene T, Marsh J, Stevens L, Kusek JV (2005) Expressing the MDRD study equation for estimating GFR with IDMS traceable (gold standard) serum creatinine values. J Am Soc Nephrol 16: 69A
Levey AS, Coresh J, Greene T, Stevens LA, Zhang YL, Hendriksen S, Kusek JW, Van Lente F (2006) Using standardised serum creatinine values in the modification of diet in renal disease study equation for estimating glomerular filtration rate. Ann Intern Med 145(4): 247-254

Levey AS, Greene T, Kusek JW, Beck GJ (2000) A simplified equation to predict glomerular filtration rate from serum creatinine. J Am Soc Nephrol 11: 155A

Levey AS, Stevens LA, Schmid CH, Zhang YL, Castro 3rd AF, Feldman HI, Kusek JW, Eggers P, Vann Lente F, Greene T, Coresh J (2009) CKD-EPI (Chronic Kidney Disease Epidemiology Collaboration). A new equation to estimate glomerular filtration rate. Ann Intern Med 150(9): 604-612

National Collaborating Centre for Chronic Conditions (2008) Chronic Kidney Disease: National Clinical Guideline for Early Identification and Management in Adults in Primary and Secondary Care. Royal College Physicians: London. http://www.renal.org/Libraries/Other_Guidlines/ NICE_73_Chronic_Kidney_Disease_2008.sflb.ashx (accessed 10 February 2011)

National Kidney Disease Education Program (2012) Chronic Kidney Disease and Drug Dosing: Information for Providers. http://nkdep.nih. gov/professionals/drug-dosing-information.htm (accessed 10 January 2012)

National Kidney Foundation (2002) K/DOQI clinical practise guidelines for chronic kidney disease: evaluation, classification and stratification. Am J Kidney Dis 39(Suppl 1): S1-S266

Plumridge RJ, Sewell GJ (2001) Dose-banding of cytotoxic drugs: a new concept in cancer chemotherapy. Am J Health Syst Pharm 58(18): 1760-1764

Poge U, Gerhardt T, Stoffel-Wagner B, Sauerbruch T, Waitas RP (2011) Validation of the CKD-EPI formula in patients after renal transplantation. Nephrol Dial Transplant 26: 4104-4108

Redal-Baigorri B, Heine Stokholm K, Rasmussen K, Jeppesen N (2011) Estimation of kidney function in cancer patients. Dan Med Bull 58(2): A4236

Rick O, Bokemeyer C, Beyer J, Hartmann JT, Schwella N, Kingreen D, Neureither S, Metzner B, Casper J, Wandt H, Hartmann F, Schmoll HJ, Derigs G, Gerl A, Berdel WE, Kanz L, Siegert W (2001) Salvage treatment with Paclitaxel, ifosfamide, and cisplatin plus high-dose carboplatin, etoposide, and thiotepa followed by autologous stem-cell rescue in patients with relapsed or refractory germ cell cancer. J Clin Oncol 9(1) 81-88

Rostoker G, Andrivet P, Pham I, Griuncelli M, Adnot S (2007) A modified Cockcroft-Gault formula taking into account the body surface area gives a more accurate estimation of the glomerular filtration rate. J Nephrol 20(5): 576-585

Seronie-Vivien S, Toullec S, Malard L, Thomas F, Durrand V, Chatelut E (2006) contribution of the MDRD equation and of cystatin C for renal function estimates in cancer patients. Med Oncol 23(1): 63-73

Shord SS, Bressler LR, Radhakrishnan L, Chen N, Villano JL (2009) Evaluation of the Modified Diet in renal disease equation for calculation of carboplatin dose. Ann Pharmacother 43(2): 235-241

Souhami R, Tobias J (2005) Cancer and its Management. 5th edn. Blackwell Scientific Publications: Oxford

Stevens LA, Schmid CH, Zhang YL, Coresh J, Manzi J, Landis R, Bakoush O, Contreras G, Genuth S, Klintmalm GB, Poggio E, Rossing P, Rule AD, Weir MR, Kusek J, Greene T, Levey AS (2010) Development and validation of GFR-estimating equations using diabetes, transplant and weight. Nephrol Dial Transplant 25(2): 449-457

Thomsen HS, European Society of Urogenital Radiology (ESUR) (2007) ESUR guideline: gadolinium-based contrast media and nephrogenic systemic fibrosis. Eur Radiol 17(10): 2692-2696

White CA, Akbari A, Doucette S, Fergusson D, Knoll GA (2010) Estimating glomerular filtration rate in kidney transplantation: is the new kidney disease epidemiology collaboration equation any better? Clin Chem 56(3): 474-477

This work is published under the standard license to publish agreement. After 12 months the work will become freely available and the license terms will switch to a Creative Commons Attribution-NonCommercial-Share Alike 3.0 Unported License. 